Carragher, BJ., Stewart, RA., Beal, CD., (2012) Quantifying the influence of residential water appliance efficiency on average day diurnal demand patterns at an end use level: A precursor to optimised water service infrastructure planning. Resources Conservation and Recycling 62, 81-90. doi:10.1016/j.resconrec.2012.02.008

\title{
Quantifying the influence of residential water appliance efficiency on daily diurnal demand patterns at an end use level: a precursor to optimised water service infrastructure planning
}

\section{Byron J. Carragher}

9 Research Associate, Smart Water Research Centre, Griffith University, Gold Coast Campus

10 4222, Australia, Email: byron.carragher@griffithuni.edu.au

11 Rodney A. Stewart

12 Director, Centre for Infrastructure Engineering and Management, Griffith University, Gold

13 Coast Campus 4222, Australia, Email: r.stewart@griffith.edu.au

14 Cara D. Beal

15 Research Fellow, Smart Water Research Centre, Griffith University, Gold Coast Campus

16 4222, Australia, Email: c.beal@griffith.edu.au

Abstract

Residential water consumption reductions resulting from water efficiency measures has received much research attention in recent years; however, research into the contribution of such measures to reductions in hourly water demand and flow-on benefits to urban water service infrastructure capital efficiency is still in its infancy. In an attempt to shed light on this issue, this study examined the degree of influence that clustered sets of 191 households participating in an Australian smart metering study, based on their weighted household water stock efficiency star rating classification (e.g. taps, shower heads, clothes washers), had on average day (AD) diurnal demand patterns at a water end use level. Results showed a statistically significant reduction in AD peak hour water consumption in homes with higher composite fixture/appliance star ratings. Paired comparison between households with a greater than three star efficiency with those of a lower star rating showed a reduction in $A D$ morning and evening peak hour demand of $15.35 \%$ and $16.64 \%$, respectively. The paper concludes with a discussion on the pipe network modelling and capital infrastructure efficiency implications derived from better understanding on the likely reductions in AD peak hour water demand, due to residential water stock efficiency measures.

35 Keywords: sustainable development, urban water planning, water efficient technology, water 


\section{Background}

\subsection{Maintaining urban water security}

40

41 Only a fraction of the $1 \%$ of freshwater on Earth is available and accessible to human 42 populations via lakes and streams, clearly indicating the extreme value of sustainably 43 managing such water resources (Bouwer, 2000). In south-east Queensland (SEQ), Australia, 44 a sustainable approach to water security has been adopted which includes a variety of urban 45 water planning schemes, including source substitution (Talebpour et al., 2011), recycled use 46 (Willis et al., 2011a) and desalination. As a part of these water planning schemes, demand management strategies are powerful least-cost approaches for conserving scarce water resources by restricting the demand or consumption of water, minimising supply system losses and maximising the efficiency of water used in specific tasks (Baroudy et al., 2005). Studies have shown that a cost effective method of demand management is the implementation of high efficiency water fixtures/appliances in residential households. This technology is also a fundamental starting point for water authorities to adopt before higher cost water supply or demand solutions are considered (Fidar et al., 2010; Stewart et al., 2011;

54 Stewart et al., 2010; Willis et al., 2010).

Of specific interest to SEQ Australia, is the increasing population, as over 750,000 new dwellings are estimated by 2032 (DIP, 2009). With current forecasts already predicting that supply may not be able to meet demand across SEQ in the near future, steps must be taken to reduce the pressure on potable water supplies (QWC, 2010). Undoubtedly, demand management strategies, such as fixture/appliance (i.e. water use stock) retrofit programs will result in potable water savings and a downward pressure on supply depletion rates, thus 62 improving urban water security.

\subsection{Water demand management}

66 Over the last decade or so, a growing number of sustainable water management strategies 67 have been implemented in Australia and abroad to ensure the secure supply of urban water 68 (e.g. Sullivan and Dawson 2008). Such water demand management strategies can 69 significantly reduce potable water demand (Inman and Jeffrey, 2006; Kennedy et al., 2008). 70 Essentially, water demand management is aimed at motivating people and their water use 
71 activities, through a range of social marketing, economic, and other conservation programs 72 (Arbués et al., 2003; Baroudy et al., 2005; Russell and Fielding 2010). These measures are 73 designed to alleviate pressure on potable supplies and protect water quality. If potable water 74 supplies diminish, as has been the case in SEQ Australia over the last decade, conservation and efficient use of water quantity and quality becomes essential (Baroudy et al., 2005). Managing water demand can be achieved through a number of wide-ranging measures or practices which include both: non-financial (awareness, water efficient technology) or financial (incentives, pricing) as well as mandatory (regulations) or optional (market systems) (Jones et al., 2010; Kenney et al., 2008). In a more holistic sense, demand management includes: (1) gaining potable water savings by maximising efficiency of use; (2) protecting the quality of water as well as matching water quality with specific water use; and (3) using non-conventional water sources such as waste water or grey water (Baroudy et al., 2005). The introduction of rebates for purchasing and installing water efficient technology has resulted in considerable savings in mains water demand (e.g. Beal et al., 2011; Willis et al., 2011a).

\subsection{Water efficient technology standards in Australia}

The Water Efficiency Labelling and Standards (WELS) system was generated as a cooperative Australian Commonwealth/State and Territory regulatory scheme to help reduce domestic water consumption (Australian Government, 2011). It became legislation in January 2006 and replaced the previously voluntary AAAAA water rating scheme (an evolution of the AA system which had been in existence since 1988). Under the WELS Australian Standard (AS6400:2005), product suppliers are required to label dishwashers, showers, washing machines, taps, urinals, toilets and flow controllers (aerators) with a star-rating as well as water efficiency information to enable consumers to choose water efficient products specific to their needs (Standards Australia, 2005). To gain a star rating, appliances must pass comprehensive and consistent tests. Tests vary depending on the individual appliance/fixture. For example, shower roses are rated on an average flow rate, toilets are rated on full flush, half flush and average flush volumes, and washing machines are rated based on water used per cycle in conjunction with load size (Australian Government, 2011).

102 Once thoroughly tested, the scheme classifies the efficiency of a particular water use 103 appliances/fixture model and allocates a star rating. Ratings are allocated in half star 104 increments up to a maximum 6 star rating; where the higher star ratings imply greater 
105 efficiency. The WELS rating scheme was designed to ensure the continued development of water efficient products and to guarantee appliances/fixtures are easily labelled to enable consumers to clearly identify and make informed decisions in regards to the purchase of water efficient products (Australian Government, 2011).

\subsection{Smart water metering and end use analysis}

112 Water end use studies provide a strong basis for evaluating the effectiveness of a range of 113 water demand management strategies, and aid water demand modelling forecasts 114 underpinning all water service infrastructure modelling and reticulation plans. Knowledge of 115 the typical water consumption volumes and the associated end uses (e.g. toilet, tap, shower, 116 clothes washer, irrigation and leaks) allow a more proactive approach to demand 117 management and can be used for targeted water conservation strategies and schemes (Barody 118 et al., 2005; Beal et al., 2011; Willis et al., 2011b). Blokker et al. (2010) states that studies 119 into water end use data, especially across seasons and regions, is the foundation for water 120 consumption predictions. They further point out that end use data would be required to 121 determine how water is consumed by residents within their home as well as aid the 122 development of demand forecasting and water distribution network models. As a means of 123 achieving this end use data, high resolution "smart" water meters have been developed and 124 are often attached to remote data logging equipment to allow for data storage and real time 125 analysis of water consumption. High resolution "smart" water meters, such as those applied 126 in this study, can provide 0.014 litres per pulse (L/pulse) data output and when attached to 127 wireless data loggers they can store and provide consumption data in five second intervals via 128 general packet radio service (GPRS) (Beal et al., 2010). In addition to the water meters, 129 household water audits and water use diaries are often conducted, in what is termed a mix 130 method approach, to allow for development of household water stock inventories and 131 accurate characterisation of residential water end uses (Beal et al., 2011; Willis et al., 2009a).

133 In recent years, a number of residential water end use studies have been completed using a 134 range of single or mixed methods, such as household auditing, diaries and high resolution 135 smart metering, with a diverse range of per capita end use summaries (Fidar et al., 2010; 136 Heinrich, 2007; Loh and Coghlan, 2003; Mayer and DeOreo, 1998; Mayer et al., 2004; Mead, 137 2008; Roberts, 2005; Sivakuman and Aramaki, 2010; Willis et al., 2011a; Willis et al., 138 2009b;). The combined average daily per capita water end use values calculated from these 
139 studies are: toilet $=24 \mathrm{~L} / \mathrm{p} / \mathrm{d}$; shower $/$ bath $=46 \mathrm{~L} / \mathrm{p} / \mathrm{d}$; clothes washing $=32 \mathrm{~L} / \mathrm{p} / \mathrm{d}$; 140 dishwasher $=2 \mathrm{~L} / \mathrm{p} / \mathrm{d} ;$ tap $=35 \mathrm{~L} / \mathrm{p} / \mathrm{d}$; leaks $=6 \mathrm{~L} / \mathrm{p} / \mathrm{d}$; and irrigation $=40 \mathrm{~L} / \mathrm{p} / \mathrm{d}$. While these 141 existing studies report average per capita end use consumption and sometimes daily diurnal 142 patterns at an end use level, none have clustered diurnal demand patterns based on the 143 household water stock efficiency star rating. This study offers the first reported attempt to 144 empirically link water stock efficiency with reductions in AD peak hour demand, and discuss 145 the implications of such peak hour demand reductions on water service pump and pipe 146 infrastructure capital efficiency.

Although there is a growing body of work that demonstrates the influence of water efficient stock on reduced household water demand (Athuraliya et al., 2008; Beal et al., 2010; Willis et al., 2010;), there is no data characterising the changes to peak daily and hourly flows by the reduction in demand from water efficient household stock. Of significant interest is how a reduction of peak demand could alleviate pressure on current supply network infrastructure and potentially defer the associated infrastructure upgrade costs. Diurnal usage patterns have been used to identify trends and peaks in water (e.g. Willis et al., 2011a) and energy (e.g. Firth et al., 2008; Taherian et al., 2010) consumption over time. In terms of diurnal water use, these patterns have aided in the characterisation of daily water consumption trends across different socio-demographic groups and varying climatic regions (Beal et al., 2011; Willis et al., 2011a). Diurnal patterns provide valuable information on demand flow rates (per capita) and end use consumption at an hourly level for AD demand in a study period. Further to this, $\mathrm{AD}$ diurnal demand patterns are vital empirical input parameters for configuring network distribution models as well as for integrated urban water planning models such as those proposed by Makropoulos et al. (2008) and Wong and Mui (2007). Stewart et al. (2010) also note that this type of peak demand analysis can provide valuable information to water utilities to address issues such as planning, billing, asset management and hydraulic engineering based problems. Other benefits of such patterns include the real-time observation of AD peaks and troughs, understanding daily supply quantities and reservoir storage needs and finally creating demand parameters for optimisation of the supply infrastructure through offsets to network upgrades (Beal et al., 2010; Stewart et al., 2010). 
175 As recorded by Beal et al. (2010), efficient front loading washing machines used significantly

176 less water $(11.3 \mathrm{~L} / \mathrm{p} / \mathrm{d}, p<0.05)$ than top loaders. Beal et al. (2010) also reported a trend 177 toward lower water consumption on a per capita and per household basis when high

178 efficiency (low flow) shower heads were installed, with results showing that shower end use 179 consumption could be reduced by nearly 20\%. Willis et al. (2010) also reported similar 180 reductions in consumption as a result of more efficient washing machines and the 181 replacement of old, high flow shower heads with more efficient low flow fittings. Other 182 studies (Athuraliya et al., 2008; Loh and Coghlan 2003; Stewart et al., 2010), have also demonstrated that stock efficiency can have a significant impact on reducing average daily water consumption.

186 Residential water use does not remain constant across a whole day but experiences periods of 187 high and low demand throughout the 24 hour period (Arbués et al., 2003). These variations in 188 water use demand can be graphically represented as diurnal usage patterns and can be used to 189 separate daily demand predictions into hourly or half-hourly periods and hence identify the 190 time at which demand is greatest (Willis et al., 2011a). The benefit of conducting a high 191 resolution end use study is that total water demand in each hourly or half-hourly period can 192 be further broken down into its contributing end uses. The availability of water stock 193 efficiency information (i.e. star rating) for each appliance/fixture in a household, and its 194 resulting AD diurnal demand pattern at an end use level, enables determination on the extent 195 to which water stock efficiency measures influence the AD peak hour demand, amongst other 196 things.

\subsection{Urban water demand modelling driving water service infrastructure planning}

Water demand modelling and forecasting has a range of purposes, which include: planning new (greenfield) developments or water distribution network expansion; estimating the capacity and operation of water storage reservoirs; pump and pipe sizing; as well as aiding decision making when addressing metropolitan water management challenges (e.g. pricing policy, water use restrictions) (Blokker et al., 2010; Bougadis et al., 2005). Application of long-term forecasting is generally required for future planning and design, whereas shortterm forecasting is most useful in management and operation. There are two general 
approaches to developing long-term or short-term forecasts: top-down modelling and bottom-

208 up modelling. The top-down demand modelling approach allocates a water demand multiplier pattern across a broad spatial scale (Blokker et al., 2010).

210

211 In essence, top-down modelling involves gathering macro information and making a series of 212 assumptions to break down the information into its components. Traditional water network 213 demand modelling often applies this top-down derived demand per equivalent tenement (ET)

214 that is also allocated to half-hour time steps based on an established residential household 215 diurnal demand pattern, which is often framed from out-of-date historical water use 216 information. This diurnal demand pattern is attached to nodes representing the number of ET 217 within the zone. In contrast to the top-down modelling approach, bottom-up demand 218 modelling assigns individual demand multiplier patterns to each tenement within a supply 219 network zone to more accurately determine demand on a smaller spatial scale (Blokker et al., 220 2010). The bottom-up modelling approach is empirically based and therefore implies that 221 information is collected on a number of smaller scale elements and aggregated together to 222 form a macro picture. Thus, high resolution end use data is ideal for such bottom-up 223 modelling and, in combination with aligned data on water efficient stock within each home, 224 better predictions on individual household AD hourly diurnal demand flow rates can be 225 formulated for varying water stock efficiency star rating levels.

227 Establishing the need for a knowledge base in this domain is the primary purpose of this 228 paper, with the long-term objective to establish a comprehensive data base of diurnal demand 229 characteristics under different situational context conditions that can be applied for more 230 precise network modelling and flow-on water service infrastructure planning.

\section{Research objectives}

234 In recent years there has been a large volume of literature that discusses the various factors 235 influencing water demand and more recently water end use consumption. However, there has 236 been no reported study to date covering the link between superior water stock efficiency and 237 reductions in $\mathrm{AD}$ peak hour demand within a household, particularly where such peak 238 demand has been disaggregated to an end use level. Specific objectives for this research 239 project were: 
(1) Development of a weighted classification method to cluster households based on their overall indoor water stock efficiency star rating;

(2) Development of AD diurnal demand patterns, on a per capita water demand basis for each end use category, for each of the sampled 191 households;

(3) Completion of a comparative assessment on the AD hourly diurnal demand patterns

\section{Research method}

253

\subsection{Study sample}

255

256

The data for the current study is generated from the South East Queensland Residential End Use Study (SEQREUS) (Beal et al., 2011) funded through the Urban Water Security Research Alliance. A total of 191 households from the larger SEQREUS sample were used in this study in order to generate their individual AD hourly diurnal demand profiles at a water end use level. These homes provided a good representation of SEQ households with a strong mix of household occupancies and family types including a range of income categories. The sample included 43 homes from the Gold Coast, 57 from Brisbane, 30 from Ipswich and 61 from the Sunshine Coast. The average daily household and per capita water consumption for the 191 participating households was 333.7 litres per household per day (L/hh/d) and 132.61 litres per person per day $(\mathrm{L} / \mathrm{p} / \mathrm{d})$, respectively (Figure 1).

\section{[INSERT FIGURE 1]}

\subsection{Household water stock efficiency weighting and clustering methods}

Household stock efficiency information was obtained from household water audits with efficiency ratings recorded as per the WELS star rating system. The efficiency information included flow rates of shower heads, average flow rates of indoor taps, and the volume of 
274 toilet cisterns, in order to establish water used per flush, star rating and water used per cycle 275 of washing machines and dishwashers. However, it was observed that the WELS rating 276 system utilised different rating methods for different appliances (e.g. average flow rates for

277 shower heads and litres per wash for washing machines) and there is wide variability in the 278 contribution of each end use to total household water consumption. As a result, it was 279 recognised that replacing a 3 star washing machine with a 4 star did not necessarily equate to 280 the same margin of savings as replacing a 3 star shower head with that having a 4 star rating. 281 For this reason, a 4 star washing machine is not comparable to a 4 star shower head in terms 282 of water savings. In an attempt to develop a representative composite star rating, reflecting 283 the combined efficiency of the entire household water appliance/fixture stock composition, a weighted classification system was designed and implemented. The overall household efficiency weighting system takes account of both the contribution of each end use to total consumption and the star rating of the various indoor fixtures/appliances within each household. Such a composite household efficiency star rating is needed to represent each household as its $\mathrm{AD}$ diurnal patterns and peak hour demand values are reflective of the combined contribution of the different water using appliance/fixtures.

Generating an average per capita end use break down enabled the identification of the most significant end uses contributing to total demand. This allowed an appropriate weighting value for each fixture/appliance to be calculated. After critical analysis of the end use break down (Figure 1b), it was determined that the composite efficiency rating system should only consider the four primary end uses (i.e. shower, clothes washer, tap and toilet) contributing to total demand. This reasoning was based on the observation that these four primary end uses were features of every home within the study, made up the lions' share of total household demand, and also had available data on specific WELS efficiency ratings. Although dishwasher could be allocated a WELS rating, it is such a small component (i.e. $<2 \%$ ) of overall household water use (Beal et al., 2011; Roberts 2005; Willis et al., 2011a) that it is unlikely to discernibly affect peak flows and was therefore not included in the composite household star rating. The four primary end uses accounted for over $87.55 \%$ of the total water use within the sample and therefore would be the significant contributors to AD peak hour diurnal flows. In effect, the weighting values applied for the composite household star rating was the four primary end use average daily demand values (Figure 1b), in percent of total demand terms, 
but adjusted to make a $100 \%$ summation of weighting factors. For example, the weighting value for the shower towards the household composite star rating was calculated as $29.57 \% \div$ $87.55 \%=0.3377$. Similarly for the other end uses contributing to the composite star rating, Equation 1 was formulated.

$$
\operatorname{HCWER}=0.2180\left(\mathrm{E}_{\text {Tap }}\right)+0.1964\left(\mathrm{E}_{\text {Toilet }}\right)+0.2479\left(\mathrm{E}_{\text {Washer }}\right)+0.3377\left(\mathrm{E}_{\text {Shower }}\right)
$$

Where:

$$
\mathrm{E}_{\text {Appliance }}=\text { WELS star rating of particular appliance/fixture in household }
$$
HCWER $=$ Household composite water efficiency star rating

As an illustrative example applying equation 1, for a home with a 4.5 star washing machine, 1 star toilet, a showerhead rated at 2 stars and an average tap fixture star rating of 3 would equate to a composite household star rating of 2.64 stars (i.e. $[0.2180 \times 3]+[0.1964 \times 1]+$ $[0.2479 \times 4.5]+[0.3377 \times 2]=2.64$ stars $)$.

After each home's overall efficiency was calculated, a cumulative frequency distribution was created in order to classify the range of household composite star rating categories and identify potential efficiency clusters (Figure 2). After assessment of the distribution of homes within the sample it was observed that homes followed a normal distribution with an obvious distinction between two groups (i.e. homes above and below a three star rating) (Figure 2). The base comparison was categorised into two main clusters; homes less than $(<)$ three stars and homes greater than or equal to $(\geq)$ three stars. In addition to the base comparison, 50 of the most efficient and 50 of the least efficient homes were also clustered for comparison, as these homes generally represented the upper and lower quartiles of the sample group. These four efficiency clusters became the sample groups from which AD diurnal demand patterns were developed in order to identify the peak hour demand differences for these cluster groupings.

\section{[INSERT FIGURE 2]}

\subsection{AD diurnal demand pattern generation and statistical analysis}

After establishing each household's overall efficiency rating and generating the subsequent efficiency clusters, AD diurnal demand patterns for each of the four above mentioned 
342 efficiency clusters were developed. AD diurnal demand patterns, at an end use level, were 343 generated using a software application specifically developed for this study, which assigns 344 each use event to hourly intervals, The primary objective for creating the clustered sample 345 AD diurnal demand patterns, was to identify the peak flow rate demand in litres per person 346 per hour per day $(\mathrm{L} / \mathrm{p} / \mathrm{h} / \mathrm{d})$ for the morning (7:00 to 10:00) and afternoon (16:00 to 19:00) 347 peak period of the day for each clustered sample based on household water stock efficiency 348 and then to compare differences statistically.

As water consumption can vary substantially across regions and within sample populations, it was crucial to statistically validate the difference in $\mathrm{AD}$ peak hour water consumption between each of the efficiency clusters. Statistical analyses ensured that any observed reduction in $\mathrm{AD}$ diurnal demand peak hour consumption was the result of a higher composite stock efficiency rating and not just sample variation. To achieve this objective, a paired sample $t$-test was applied to assess the level of statistical significance for mean differences between $\mathrm{AD}$ peak hour demand values associated with the two different groupings of efficiency cluster distributions (i.e. $<3$ star compared to $\geq 3$ star composite rating clusters; and 50 most compared to 50 least efficient homes).

\section{Results and discussion}

\subsection{Impact of water efficient technology on diurnal end use patterns}

Household composite star ratings for the 191 homes were calculated using the above described method. Overall, composite star ratings ranged from the least efficient home of 1.34 stars to the most efficient home of 4.36 stars. The demographics and average household efficiency for each cluster is presented in Table 1.

[INSERT TABLE 1]

AD diurnal demand patterns, at an end use level of resolution, allowed the identification of the end uses that contributed to peak demand flow rates and the degree of influence that higher stock efficiency has on peak hour demand to be empirically observed. The AD diurnal demand pattern for each respective household star rating efficiency cluster (Table 1) is

375 presented in Figures 3 to 6 . These patterns illustrate the AD per capita hourly flow rate for 
each efficiency cluster, as well as the contribution of each end use to the total hourly consumption. The horizontal axis represents the daily time step per hour (0:00 to 24:00 hour)

378 and the vertical axis represents the water consumption in litres per person per hour per day $379(\mathrm{~L} / \mathrm{p} / \mathrm{h} / \mathrm{d})$.

Examination of the less than three star efficiency cluster diurnal demand pattern (Figure 3) showed a peak morning demand between 8:00 and 9:00 of $12.37 \mathrm{~L} / \mathrm{p} / \mathrm{h} / \mathrm{d}$. The bulk of water consumption during the morning peak hour was identified as shower and clothes washer use which, when added together, contributed to over $65 \%$ of the total demand. The less than three star homes experienced a less dramatic evening peak demand between 18:00 to 19:00 of 9.31 $\mathrm{L} / \mathrm{p} / \mathrm{h} / \mathrm{d}$. The primary contributor to this afternoon peak demand was shower consumption which contributed to over $43 \%$ of total water use in that particular peak hour (Figure 3). Tap, toilet and clothes washer use all exhibited fairly constant use over the course of the afternoon and into the evening (15:00 to 19:00).

[INSERT FIGURE 3]

The same trend was shown in Figure 4 for the greater than three star cluster, although this pattern showed a slightly later and less dramatic morning peak flow rate (between 9:00 and 10:00) of $10.47 \mathrm{~L} / \mathrm{p} / \mathrm{h} / \mathrm{d}$, when compared with the less than three star cluster. The bulk of the water consumption during the morning peak period was again primarily composed of shower and washing machine use, however greater tap and toilet consumption occurred which contributed to over $27 \%$ of the peak hour demand. A distinct feature of this particular diurnal pattern is the substantial shower use in the 7:00 to 8:00 hour period which caused acceleration in the rate of water consumption over the course of the morning (Figure 4). The afternoon peak occurs between 18:00 and 19:00 with a demand value of $7.76 \mathrm{~L} / \mathrm{p} / \mathrm{h} / \mathrm{d}$ which had a noticeable reduction in shower demand in this peak hour, when compared to Figure 3 $403 \quad(<3$ star cluster). between 9:00 and 10:00 of $11.71 \mathrm{~L} / \mathrm{p} / \mathrm{h} / \mathrm{d}$ (Figure 5). Although this is the peak flow rate for the morning (between 7:00 and 10:00), water demand was almost constant with the diurnal 
410 pattern displaying a flattened and extended peak. The most predominant end uses

411 contributing to this extended morning peak period were shower and clothes washer which

412 accounted for over $65 \%$ of the use (Figure 5). For the 50 least efficient homes, a large

413 increase in clothes washer consumption occurred between the hours of 9:00 and 11:00.

414 During this period, clothes washing accounted for over $40 \%$ of water use. This large

415 percentage may be a result of low efficiency washing machines (i.e. high volume required per

416 wash) that were generally found in the 50 least efficient homes (Figure 5). The afternoon

417 peak occurred between 18:00 and 19:00 with a flow rate of $9.65 \mathrm{~L} / \mathrm{p} / \mathrm{h} / \mathrm{d}$. Water use in the

418 peak afternoon hour was enhanced by a large amount of shower use although there was also

419 consistent underlying washing machine, tap and toilet related demand across the afternoon

420 hours of the day (Figure 5).

421

422

[INSERT FIGURE 5]

423

424 The AD diurnal pattern for the 50 most efficient homes displayed distinct double peak 425 morning usage (Figure 6). The initial morning peak, with a flow rate of $9.12 \mathrm{~L} / \mathrm{p} / \mathrm{h} / \mathrm{d}$ occurred

426 between 6:00 and 7:00 which was outside the normal peak usage period of 7:00 to 10:00

427 displayed in the other AD diurnal patterns. The second morning peak occurred between 9:00

428 and 10:00 with a flow rate of $8.48 \mathrm{~L} / \mathrm{p} / \mathrm{h} / \mathrm{d}$. This double peak scenario could be a result of two

429 different types of families within the sample; those smaller working families who leave early

430 for work in the morning and larger families with school aged children who tend to leave the

431 home later and use more water in the later part of the morning. Afternoon peak consumption

432 occurred between 18:00 and 19:00 with a flow rate of $8.30 \mathrm{~L} / \mathrm{p} / \mathrm{h} / \mathrm{d}$ with considerably more

433 shower use than the 50 least efficient homes. Interestingly, the difference in morning and

434 afternoon peaks for the 50 most efficient homes is very small when compared to the other AD 435 diurnal pattern.

[INSERT FIGURE 6]

438

439 Comparison of the AD diurnal demand patterns for the greater and less than three star 440 efficiency clusters and the 50 most and least efficient household clusters are presented in 441 Figures 7 and 8, respectively. As can been seen from these figures, flow rates for the less 442 efficient homes is greater than that of the more efficient homes for most hours of the day; 443 especially during the morning and afternoon peak periods of demand, which is the critical 
444 periods underpinning water service infrastructure design. As shown in Figure 7, the reduction

445 in the peak water consumption due to the household composite star rating for the sample

446 being greater or equal to 3 was $15.35 \%$ for the morning and $16.64 \%$ for the afternoon. The

447 largest difference in water consumption between the two water efficiency clusters occurred

448 between 7:00 and 8:00 where a difference of $3.39 \mathrm{~L} / \mathrm{p} / \mathrm{h} / \mathrm{d}$ was recorded (Figure 7).

\section{[INSERT FIGURE 7]}

452 For comparison between the 50 most and least efficient homes (Figure 8), the reduction in the 453 peak morning consumption, due to the more water efficient homes, was $22.35 \%$. Moreover, 454 there was a $13.98 \%$ reduction in peak afternoon consumption (Figure 8). The largest 455 difference in water consumption between the 50 most and least efficient homes occurred 456 between 8:00 and 9:00 with a mean sample reduction of $3.66 \mathrm{~L} / \mathrm{p} / \mathrm{h} / \mathrm{d}$.

\section{[INSERT FIGURE 8]}

Further examination into differences in water consumption between peak morning and 461 afternoon water demand periods was also conducted. Figure 9 illustrates the highest periods of use (7:00 to 10:00 and 16:00 to 19:00) where the impact of stock efficiency was clearly evident and dramatic savings in AD peak hour demand was realised.

In the hourly intervals between 7:00 and 10:00 ( 3 hour period) the greater than three star homes had a reduced average hourly consumption reduction of $2.47 \mathrm{~L} / \mathrm{p} / \mathrm{h} / \mathrm{d}(19.29 \%)$ which was statistically significant $(p<0.01)$. Similarly, the 50 most efficient homes produced an average reduction in the peak morning period (7:00 to 10:00) consumption flow rate of 3.52 $\mathrm{L} / \mathrm{p} / \mathrm{h} / \mathrm{d}(18.56 \%)$ which was also statistically significant $(p<0.01)$.

In the afternoon peak period of 16:00 to 19:00 (3 hours) consumption for the greater than three star efficiency cluster was also statistically lower $(p<0.01)$, at an average of 1.53 $\mathrm{L} / \mathrm{p} / \mathrm{h} / \mathrm{d}(28.28 \%)$, than the less than three star efficiency cluster. The 50 most efficient homes

476 afternoon peak period consumption had reduced by an average flow rate of $1.63 \mathrm{~L} / \mathrm{p} / \mathrm{h} / \mathrm{d}$ 477 (18.64\%), which was also statistically significant $(p<0.05)$. 


\subsection{Implications of reduced residential peak water demand}

481 Reduced peak demand flow rates have substantial implications to water distribution 482 networks. There is the potential for significant capital efficiency opportunities derived from 483 the potential for smaller diameter pipe infrastructure in new developments as well as 484 providing a basis for deferring an existing supply network's inevitable future upgrade costs. 485 When honing in on the study findings here, which indicate that stock efficiency measures not 486 only reduce total demand but AD peak hour demand, this presents the case for widespread 487 review and refinement of diurnal demand parameters often used in network modelling studies 488 by engineering consultants. Such refinements are especially necessary post-implementation 489 of large scale water efficiency retrofit programs (e.g. showerhead to toilet retrofit programs).

491 As empirically demonstrated herein, highly efficient water appliances and fixtures not only 492 contribute to reduced use of potable water supplies but also lower the AD peak hour demand 493 from which water supply infrastructure is designed. By increasing the aggregate star rating of 494 households in a suburb or across a city, through efficient water appliance/fixture retrofit 495 programs, there will be ongoing reduced peak period demand, which therefore means reduced 496 pressure on existing network infrastructure. Crucial network infrastructure such as pump 497 stations and trunk mains are designed to cope with fluctuations in the demand of water 498 however; as populations grow, these elements of the supply network are required to move 499 larger volumes of water in peak periods of demand and subsequently require upgrading. By 500 reducing peak demand flow rates, less strain would be placed on current pump and pipe 501 infrastructure thus offsetting the need for imminent upgrades. Not only would these potential 502 offsets save large capital costs but also save energy and further running costs as the smaller 503 sized pumps would remain in use for a longer period of time. Storage reservoirs would also 504 see longer draw down periods through decreased demand offsetting the need for necessary 505 upgrades. Adding to the current demand on pipe networks in existing areas are public works 506 and higher density residential developments. Multi-residential dwellings, high rises, hospitals 507 and other major construction projects all add to increased pipe network demand and when 508 constructed within local supply zones, place added pressure on existing pumps and pipes, 509 often reducing pressure requirements to values that are lower than prescribed standards. 510 However, instead of the traditional network modelling and capital intensive reticulation 511 option often followed by water businesses, there are opportunities to implement water stock 
512 efficiency programs in targeted regions where such development is occurring in order to 513 reduce the peak periods of consumption as demonstrated herein. This would be a particularly 514 attractive strategy if it is known that the existing household water stock appliance mix in the 515 water supply area examined is generally of a low efficiency rating (i.e. similar to the lowest 51650 efficiency cluster in this study). In addition to targeted water conservation programs such 517 as improving household water stock efficiency, there are a range of source substitution

518 schemes (e.g. internally plumbed rain tanks) which can also be concurrently implemented in 519 order to derive even further reductions in peak demand and to further extend existing 520 infrastructure upgrade requirements.

521

\subsection{Combining water demand management and source substitution strategies}

523

524 In many urban centres in Australia, and similar water insecure regions across the globe, there 525 is increasing regulation and social pressure to implement potable source substitution 526 measures such as internally plumbed rain tanks or the reticulation of advanced recycled water 527 (i.e. Class $\mathrm{A}^{+}$recycled water to certain fit-for-purpose end uses). With estimates indicating a $52830 \%$ reduction in daily per capita demand as a result of internally plumbed rain tanks in 529 Queensland, Australia (Beal et al., 2010), the coupling effect of having both a potable source 530 substitution measure and high efficiency water appliances would reduce AD peak hour 531 demand much further than reported herein. Moreover, stock efficient appliances would also 532 lengthen the draw down period of these rain tanks thereby extending the period in which their 533 supplied end uses are not requiring potable water from the town water scheme.

535 Rain tanks and recycled water supplies reticulated to fit-for-purpose residential end uses such 536 as irrigation can have a notable reduction in a home's potable demand, particularly in the hot 537 and/or dry seasonal periods (Beal et al., 2010; Talebpour et al., 2011; Willis et al., 2011a). As 538 irrigation events are some of the primary causes of the yearly peak hour demand parameters 539 used in pipe network models, especially in the warmer summer months, wide scale 540 implementation of such source substitution strategies in combination with improved stock 541 efficiency have a number of water service infrastructure capital efficiency benefits often not 542 considered by water businesses and government agencies when planning alternative supply 543 schemes. Furthermore, the implementation of these combined water conservation strategies 544 would enable the delay of costly upgrades to urban water service network infrastructure. 


\section{Conclusions}

548 This study has investigated the impact of efficient household water fixtures/appliances (i.e. 549 taps, shower heads, clothes washers and toilets) on AD peak hour demand diurnal patterns for 550 a sample of 191 homes in SEQ, Australia. Through measurement of residential water end use 551 consumption, it was established that higher household water appliance stock efficiency 552 reduced water demand by up to almost 25\%, when compared to the lesser efficient 553 households in the peak hour periods. The statistically significant reductions in peak hour 554 demand flow rates reported in this study provide the necessary evidence for water businesses 555 to explore alternatives to capital intensive upgrades in existing water supply zones. This study 556 provides empirical evidence that supports the implementation of residential efficient 557 household appliance/fixture retrofit programs, which will effectively reduce the critical peak 558 demand values used in network modelling design, and defer urgent water service 559 infrastructure upgrade requirements. This suggests excellent capital efficiency opportunities

560 for water supply infrastructure, specifically through the deferral of future upgrade costs in 561 existing areas, and the potential decrease in sizing for new network distribution elements in 562 growing population areas.

563

564 As a result of the likelihood of considerably lower peak flows in future developments, 565 particularly where development codes mandate the installation of water efficient technology, 566 it is recommended that future network modelling tasks completed by engineers incorporate 567 real reductions in future demand flow rates as well as reduced network peaking factors as a 568 result of water efficient technology.

\section{Acknowledgements}

572 This research was undertaken as a part of the South-East Queensland Residential End Use 573 Study (SEQREUS) that has been funded by the Urban Water Security Research Alliance 574 (UWSRA). Thanks also go to Dr Andrew Huang for technical assistance and advice.

\section{References}

577 Arbués F, García-Valiñas MA, Martínez-Espiñeira R. Estimation of residential water 578 demand: A state-of-the-art review. Journal of Socio-Economics 2003; 32: $81-102$. 
579 Athuraliya A, Gan K, Roberts P. Yarra valley water 2007 appliance stock and usage patterns $580 \quad$ survey. Yarra Valley Water, Melbourne, Australia; 2008.

581 Australian Government. Water efficiency labelling standards (WELS) scheme, Australian 582 Government, Canberra, Australia, viewed 10/06/2011 <http://www.waterrating.gov.au; 5832011

584 Baroudy E, Lahlou A, Attia B. Managing water demand: policies, practices and lessons from 585 the Middle East and North Africa forums. IWA Publishing: Cornwell, USA; 2005.

586 Beal C, Stewart RA, Huang T, Rey E. SEQ residential end use study. Water: journal of the $587 \quad$ Australian Water Association 2011; 38: 80 - 84.

588 Beal C, Stewart RA, Huang T. South-east Queensland residential end use study: baseline 589 results - winter 2010. Urban Water Security Research Alliance Technical Report No. 31; $590 \quad 2010$.

591 Blokker E, Vreeburg J, Van Dijk J. Simulating residential water demand with a stochastic 592 593 end use model. Journal of Water Resources Planning and Management 2010; 136: 19 26.

Bougadis J, Adamowski K, Diduch R. Short-term municipal water demand forecasting. 595 Hydrological Processes 2005; 19: 137 - 148.

596 Bouwer H. Integrated water management: emerging issues and challenges. Agricultural 597 Water Management 2000; 45: $217-228$.

598 Department of Infrastructure and Planning. South-east Queensland Regional Plan 2009 599 2031. Queensland Government, Brisbane, Australia; 2009.

600 Firth S, Lomas K, Wright A, Wall R. Identifying trends in the use of domestic appliances 601 from household electricity consumption measurements. Energy and Buildings 2008; 40: $602926-936$.

603 Fidar A, Memon F, Butler D. Environmental implications of water efficient micro604 components in residential buildings. Science of the Total Environment 2010; 408: $5828-$ $605 \quad 5835$.

606 Inman D, Jeffrey P. A review of residential water conservation tool performance and 607 influences on implementation effectiveness. Urban Water Journal 2006; 3: 127 - 143. 
Jones N, Evangelinos K, Gaganis P, Polyzou, E. Citizen's perceptions on water conservation policies and the role of social capital. Water Resources Management 2010; 25: 509 - 522.

610 Kenney DS, Goemans C, Klein RA, Lowrey J, Reidy, K. Residential water demand 611 management: lessons from Aurora, Colorado. Journal of the American Water Resources $612 \quad$ Association 2008: 44: $192-207$.

613 Heinrich M. Water end use and efficiency project (WEEP) - final report. Branz Study Report 614 No. 159, Judgeford, New Zealand; 2007.

615 Loh M, Coghlan P. Domestic water use study in Perth, Western Australia 1998 to 2000. $616 \quad$ Water Corporation of Western Australia, Perth, Australia; 2003.

617 Makropoulos CK, Natsis K, Liu S, Mittas K, Butler D. Decision support for sustainable 618 option selection in integrated urban water management. Environmental Modelling \& $619 \quad$ Software 2008; 23: $1448-1460$.

620 Mayer PW, DeOreo, WB. Residential end uses of water. Aquacraft Inc. Water Engineering and Management, Boulder, USA; 1998.

Mayer P, DeOreo W, Towler E, Martien L, Lewis, D. Tampa water department residential water conservation study: the impacts of high efficiency plumbing fixture retrofits in single-family homes. Aquacraft Inc. Water Engineering and Management, USA; 2004.

Mead N. Investigation of domestic end use. Honours Thesis, Faculty of Engineering \& Surveying, University of Southern Queensland, Toowoomba, Australia; 2008.

Queensland Water Commission. South-east Queensland water strategy 2010. Queensland

Russell S, Fielding K. Water demand management research: a psychological perspective.

Roberts P. Yarra valley water 2004 residential end use measurement study. Yarra Valley Water Commission, Brisbane, Australia; 2010.

633 Sivakumaran S, Aramaki T, Estimation of household water end use in Trincomalee, Sri $634 \quad$ Lanka. Water International 2010; 35: 94 - 99.

635 Standards Australia - AS6400 water efficient products - rating and labelling, viewed 636 07/06/2011, http://www.saiglobal.com; 2005. 
Stewart RA, Willis R, Giurco D, Panuwatwanich K, Capati, G. Web based knowledge management system: linking smart metering to the future of urban water planning. Australian Planner 2010; 47: 66 - 74.

Stewart RA, Willis RM, Panuwatwanich K, Sahin O. Showering behavioural response to alarming visual display monitors: Longitudinal mixed method study. Journal of Behaviour and Information Technology 2011; i-First Article, DOI: 10.1080/0144929X.2011.577195.

Sullivan J, Dawson R. BASIX: building water efficiency in NSW: results from the first 5 years of BASIX. Sydney Water, NSW Department of Planning; 2008.

Taherian S, Pias M, Coulouris G, Crowcroft J. Profiling energy use in households and office spaces. In Conferences Proceedings of e-Energy 2010; April 13-15, Passau, Greece.

Talebpour M, Stewart R, Beal C, Dowling B, Sharma A, Fane S. Rainwater tank end usage and energy demand: a pilot study. Water: Journal of the Australian Water Association $2011 ; 38(1): 85-89$.

Willis RM, Stewart RA, Williams PR, Hacker CH, Emmonds SC, Capati G. Residential

Willis R, Stewart RA, Panuwatwanich K, Capati B, Giurco D. Gold Coast domestic water impact of socio-demographic factors and efficient devices on end use water consumption: case of Gold Coast Australia. In Proceedings of the 5th IWA Specialist Conference 'Efficient 2009' 2009b; IWA, Sydney, Australia. 
670 Table 1. Household composite efficiency rating cluster descriptive statistics

\begin{tabular}{lrrrr}
\hline Efficiency cluster & $\begin{array}{r}\text { No. of } \\
\text { homes }\end{array}$ & $\begin{array}{r}\text { No. of } \\
\text { people }\end{array}$ & $\begin{array}{r}\text { Ave. No. of } \\
\text { people per home }\end{array}$ & $\begin{array}{r}\text { Ave. composite star } \\
\text { rating (No. of stars) }\end{array}$ \\
\hline All homes & 191 & 508 & 2.66 & 2.88 \\
$<$ three star & 102 & 271 & 2.66 & 2.40 \\
$\geq$ three star & 89 & 237 & 2.66 & 3.43 \\
50 least efficient homes & 50 & 137 & 2.74 & 2.03 \\
50 most efficient homes & 50 & 138 & 2.76 & 3.64 \\
\hline
\end{tabular}

671

672

673

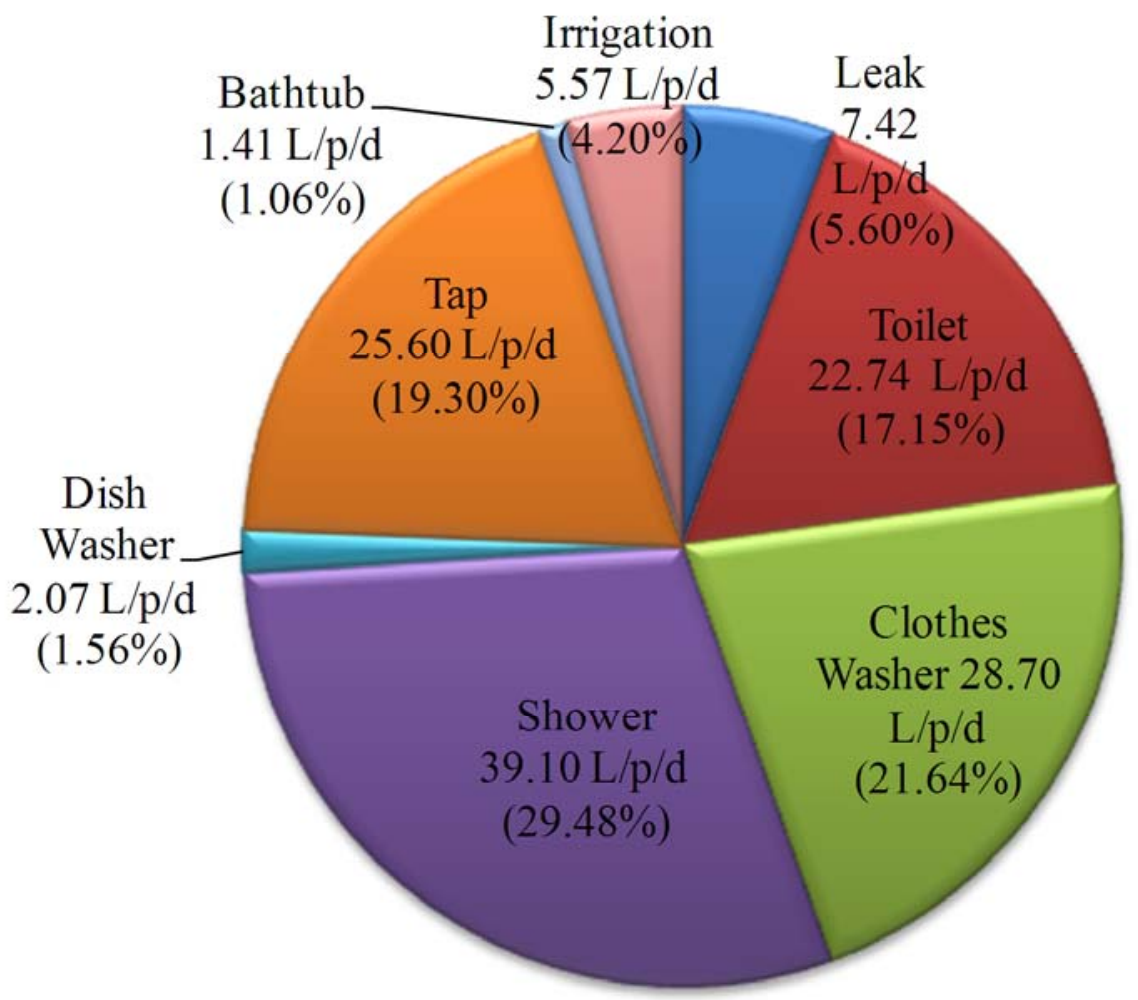

675 Figure 1. Location and end use break down of homes used in the study 


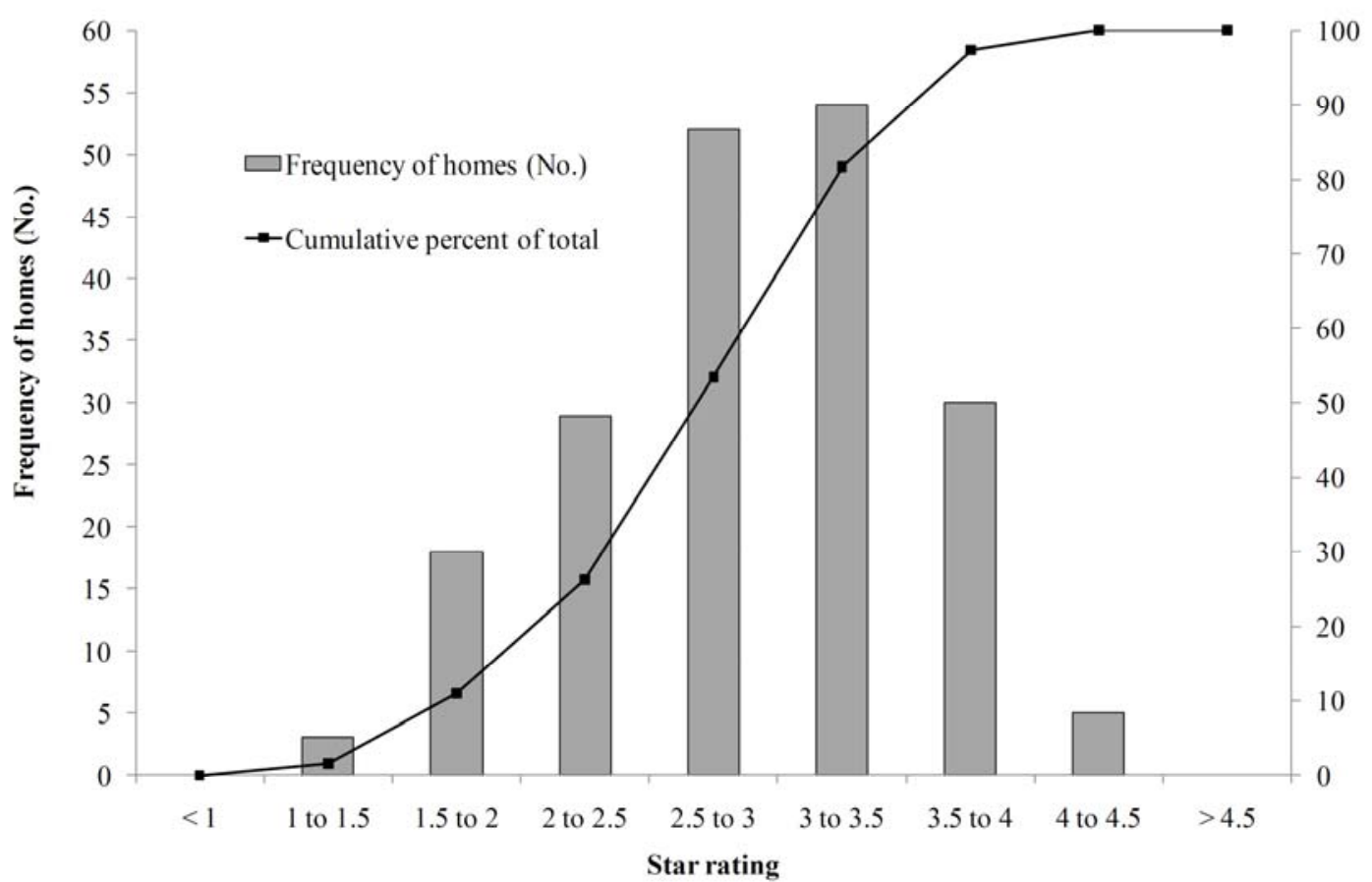

678

Star rating

679 Figure 2. Household efficiency frequency distribution

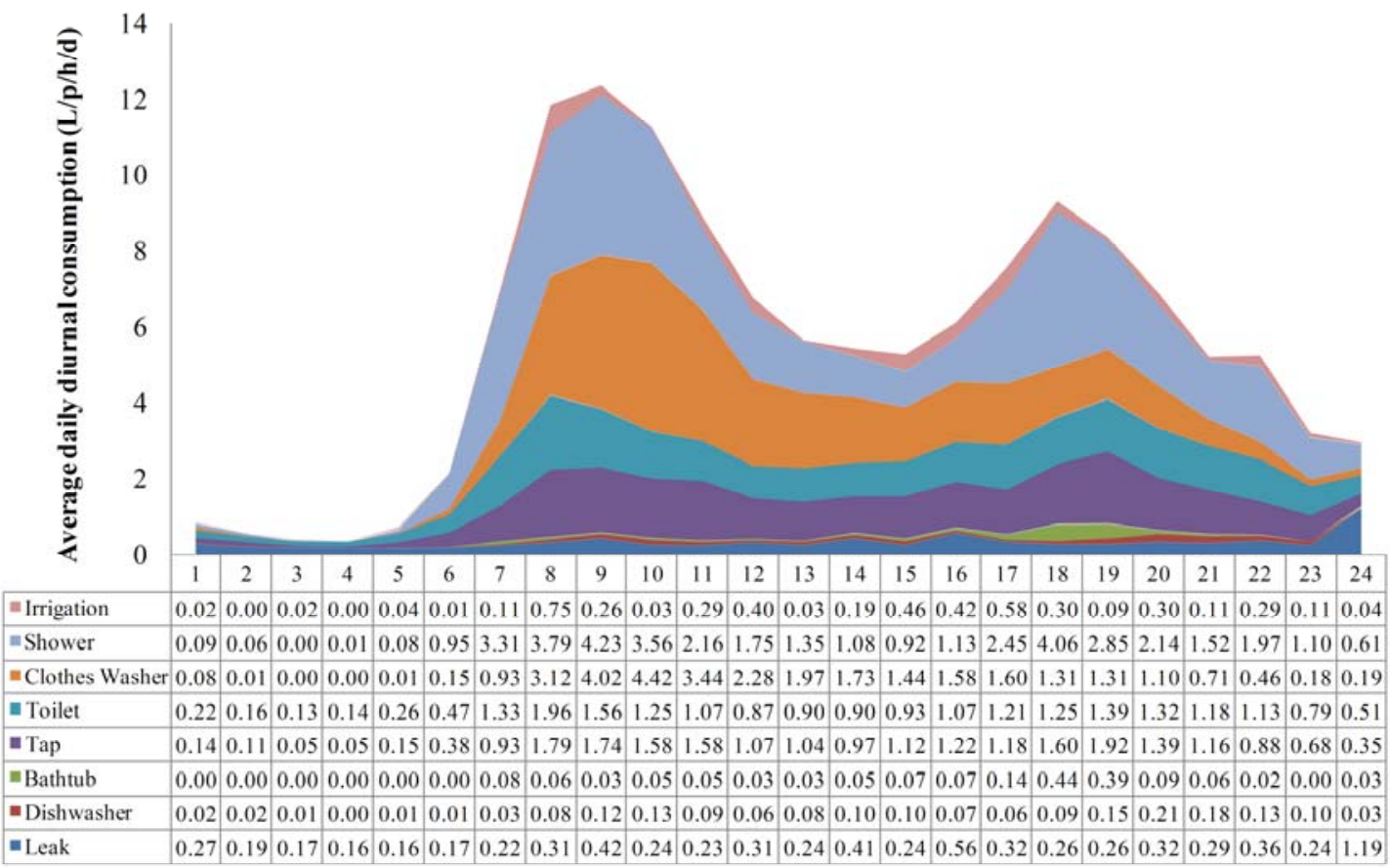

Time (0:00 hours)

681 Figure 3. AD diurnal demand pattern for households with a less than three star rating 


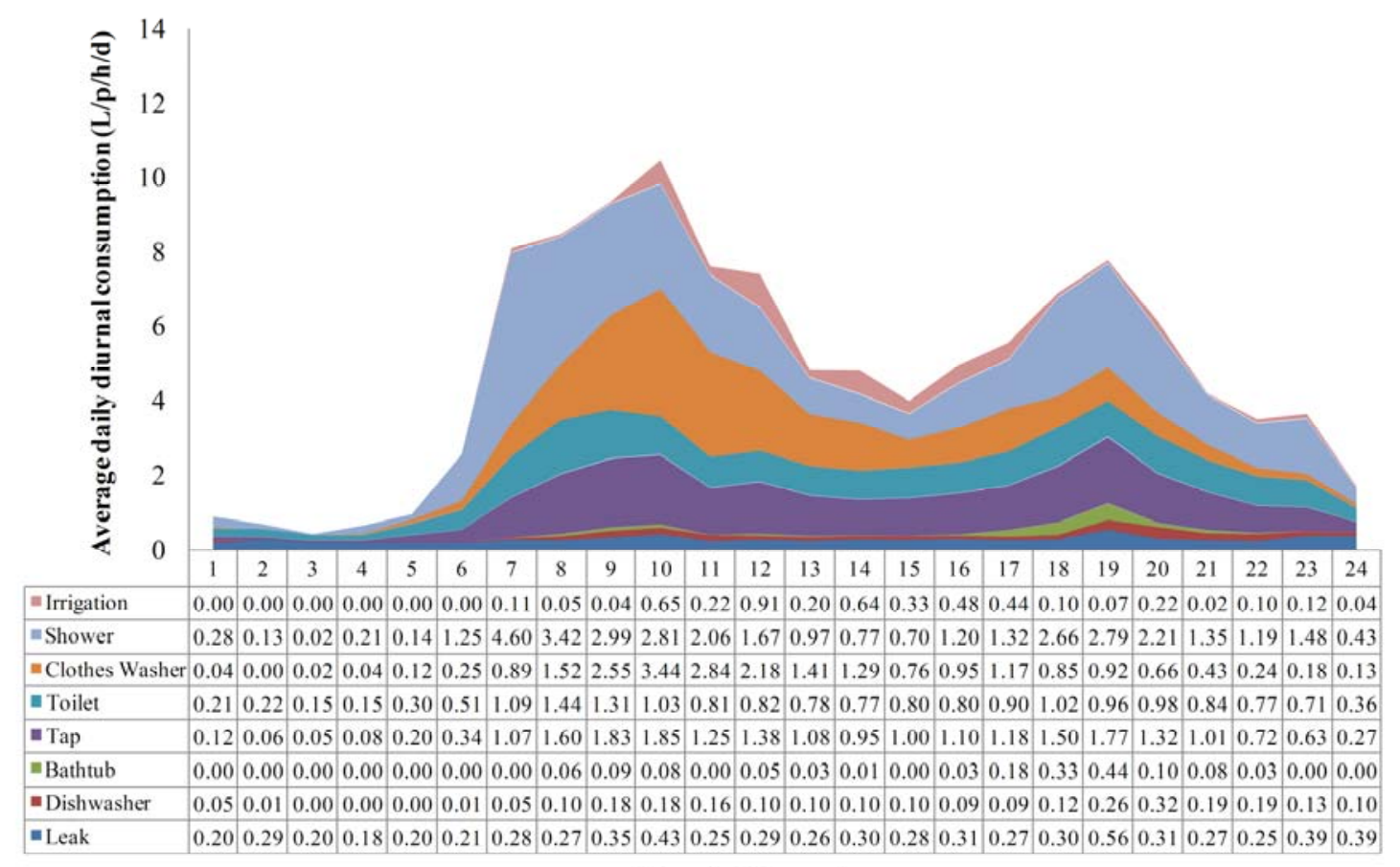

Time (0:00 hours)

686 Figure 4. AD diurnal demand pattern for households with greater or equal to three star rating

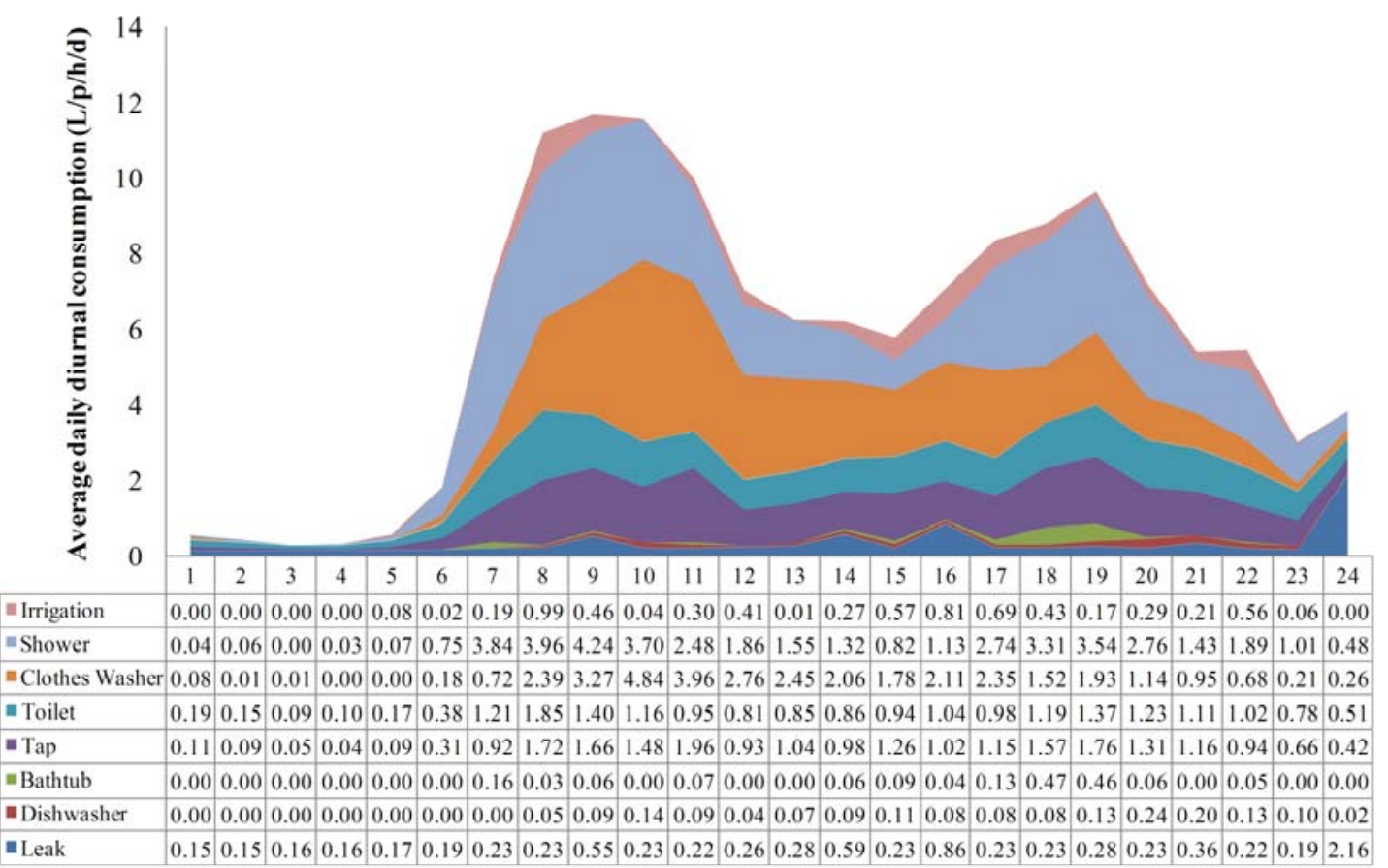

Time (0:00 hours)

688 Figure 5. AD diurnal demand pattern for 50 most efficient households in sample 


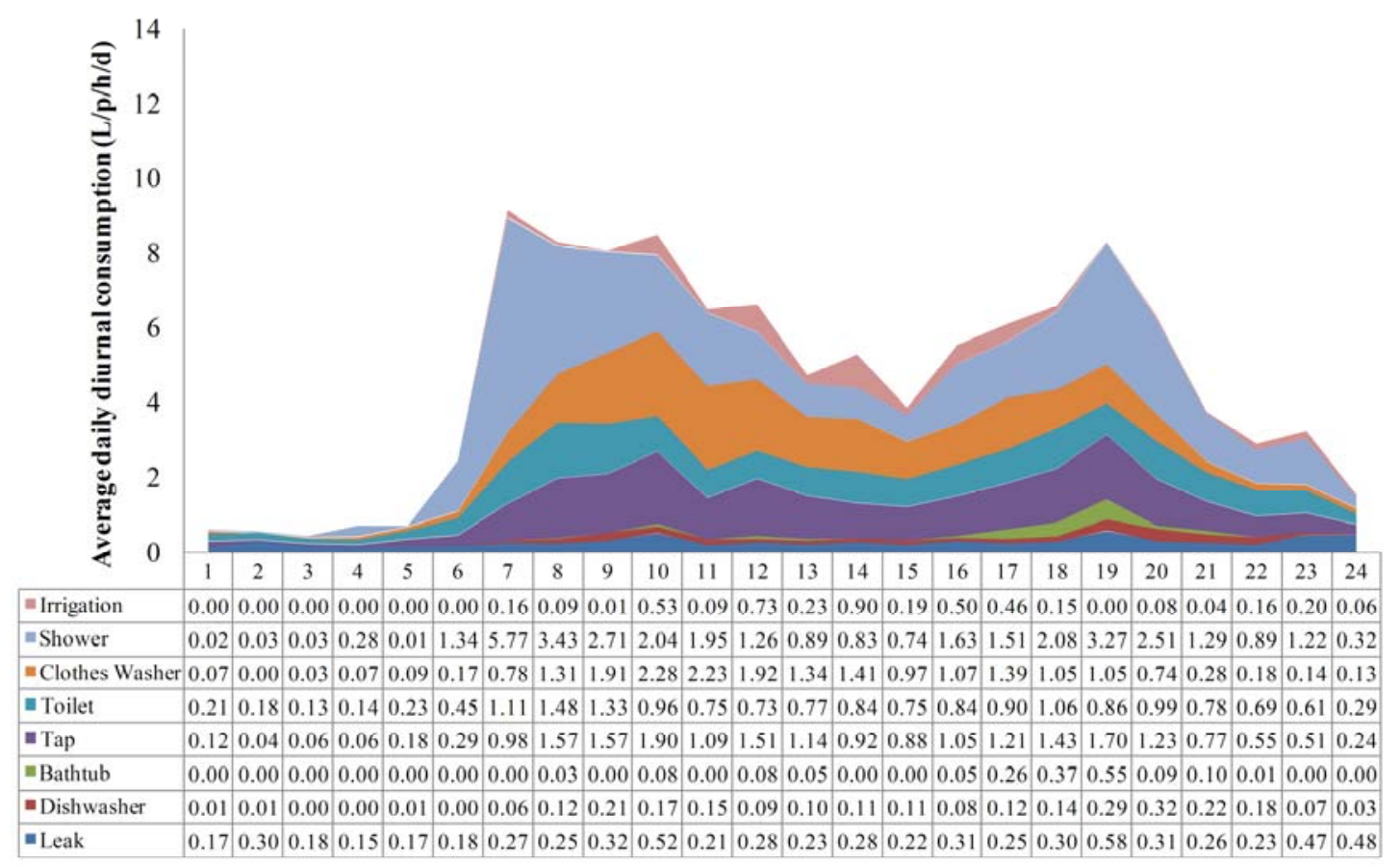

Time (0:00 hours)

693 Figure 6. AD diurnal demand pattern for 50 least efficient households in sample

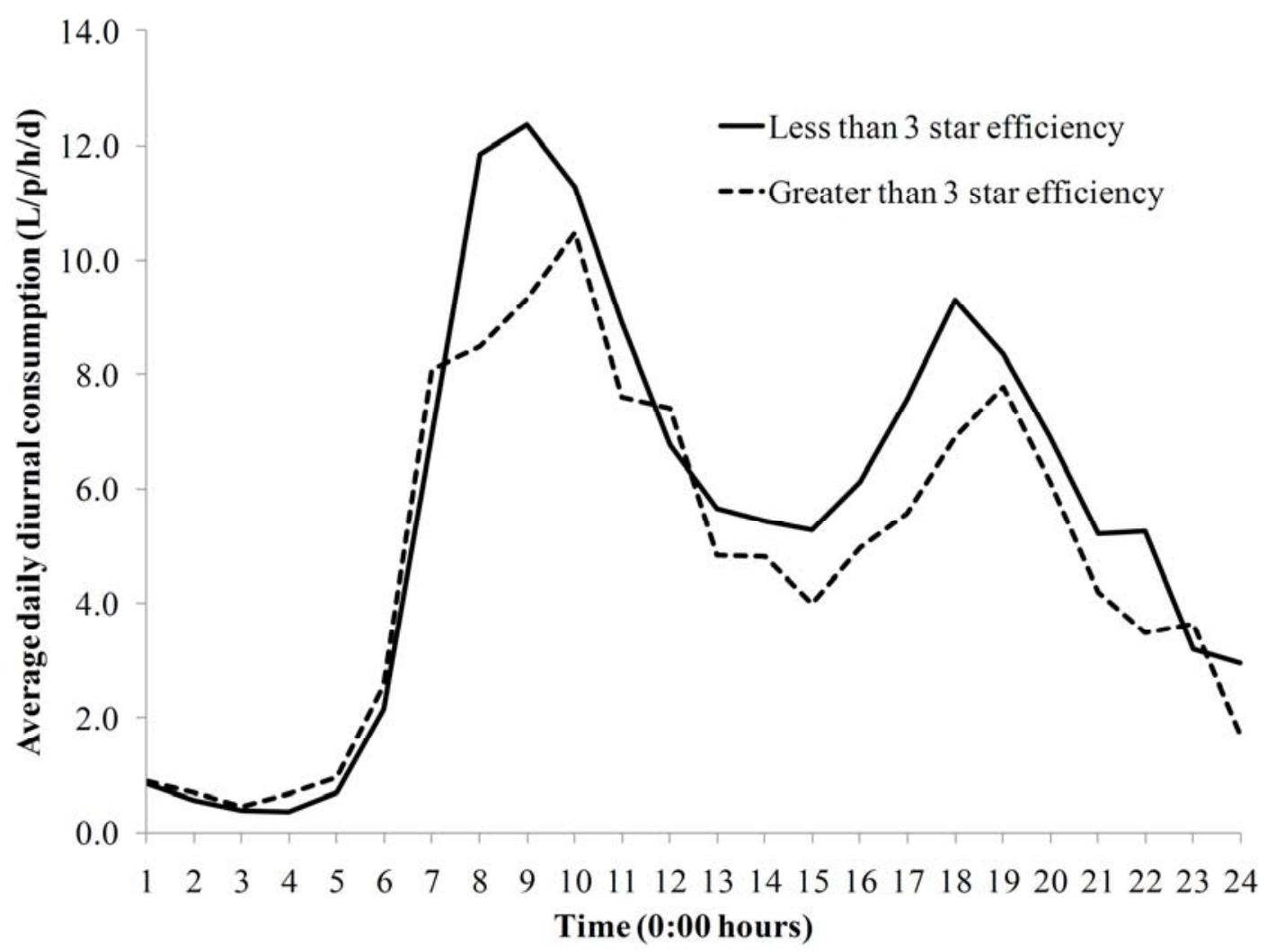
Time (0:00 hours)

695 Figure 7. AD diurnal demand pattern comparison for household clusters of greater and less 696 than a three star rating 


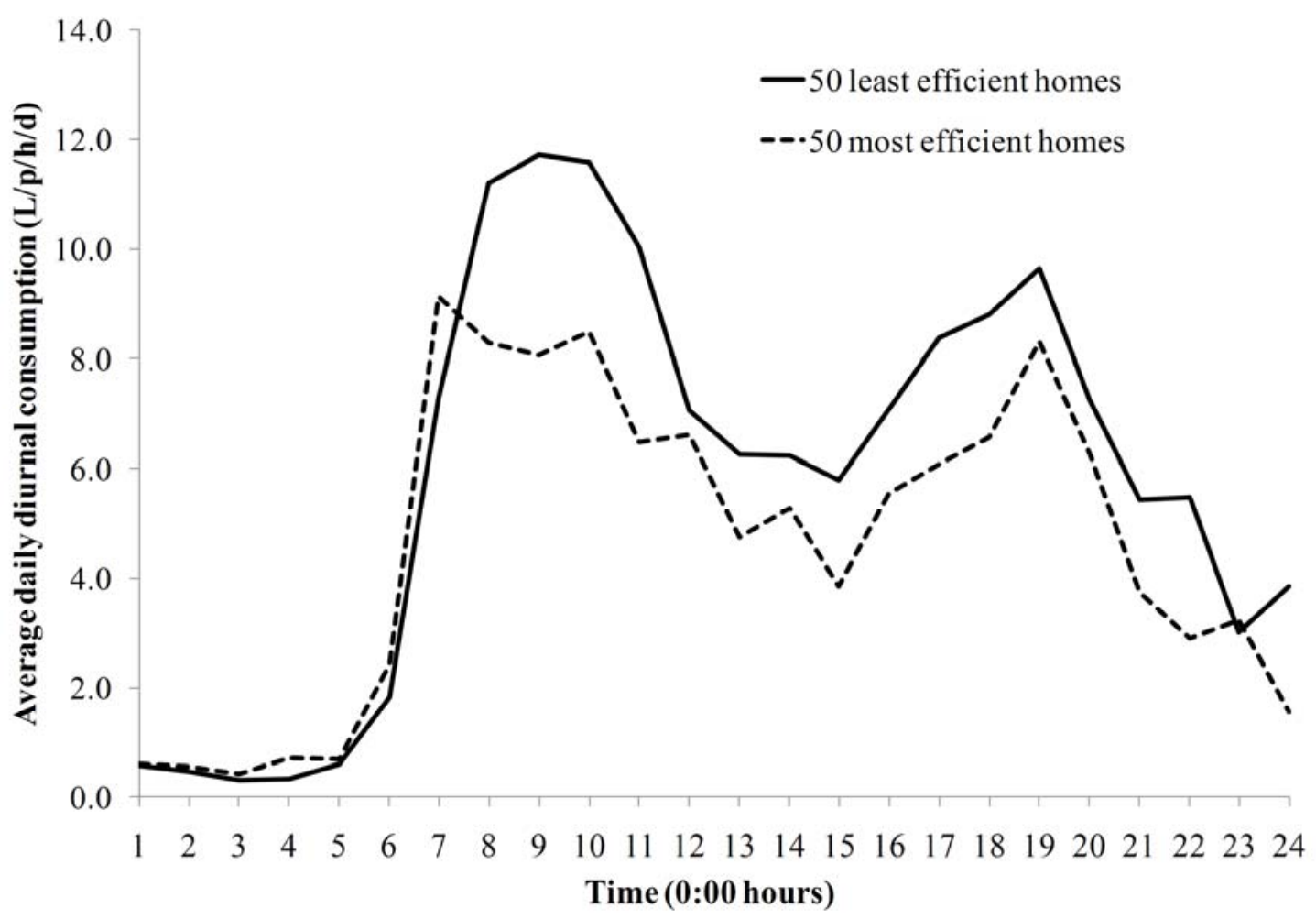

697

698 Figure 8. AD diurnal demand pattern comparison of 50 least and most efficient homes 699

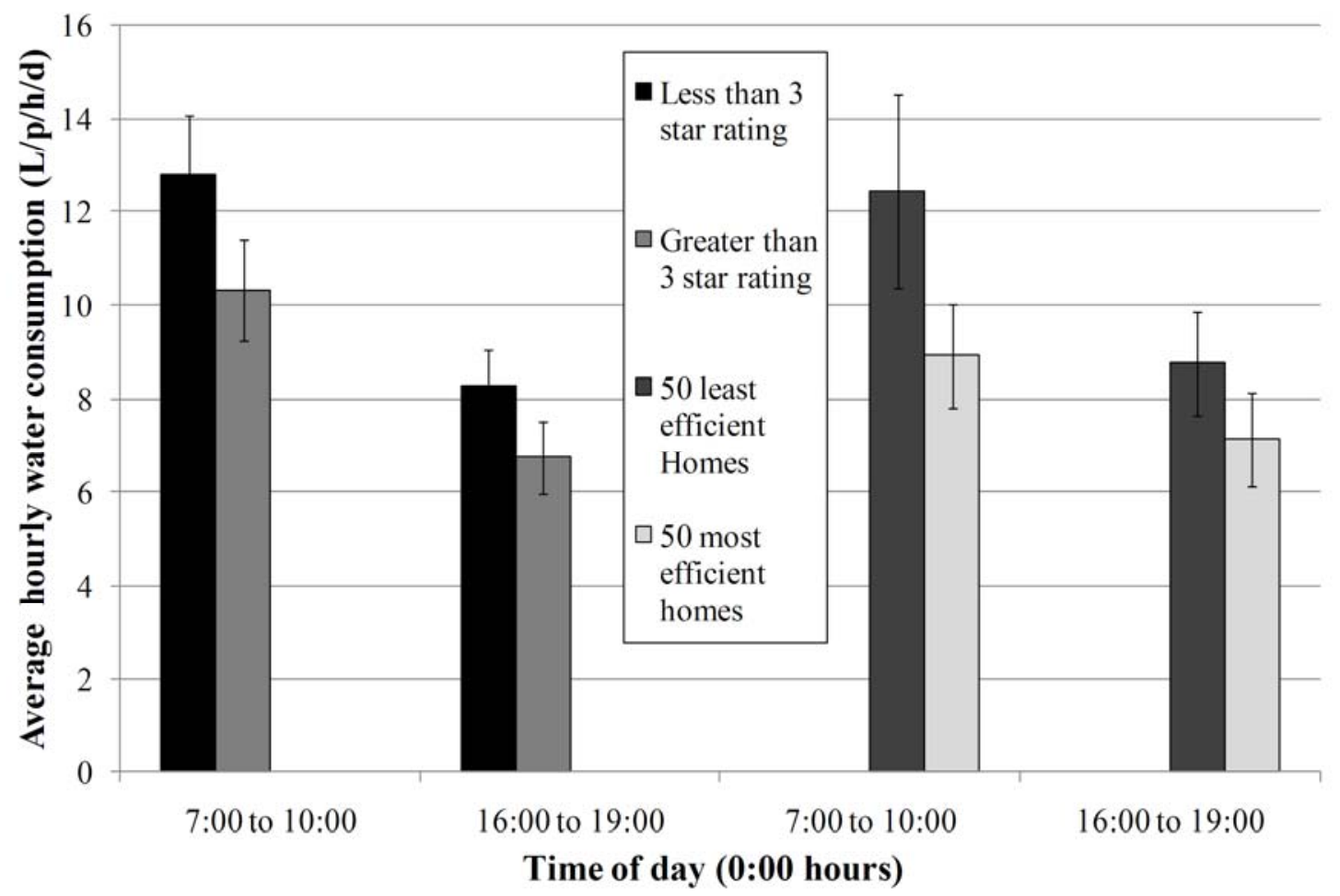

Figure 9. Efficiency cluster comparison for peak morning and afternoon periods 